\title{
A Examination of Cardio Disease Patients in Coimbatore Region and Discussion of Current Epidemiology and Future Direction
}

\author{
A. Zechariah Jebakumar, R. Ravanan
}

\begin{abstract}
Cardiovascular disorders (CVDs) are currently developing the principle wellspring of mortality in Coimbatore Region. A fourth of all mortality is infer-able from CVD. Ischemic heart and coronary disease are the extraordinary sources and are liable for $>60 \%$ of CVD (Cardiovascular afflictions) passing [1]. The World Difficulty of Studed Disease study measure of age-systematized CVD destruction pace of 27 for each 1000 masses in Coimbatore Region is higher than the overall ordinary of 430 for each 1.928 million people [2]. A couple of parts of the CVD disease in Coimbatore Region are explicit explanations behind worry, with its enlivened improvement, the early time of ailment starting with the people, and the high case loss rate [7]. In Coimbatore Region, the epidemiological change of pervasively cardio disease situations in non situations sicknesses consumes happened completed a to some degree short time allotted. Less than ideal mortality with respect to significant stretches of life lost in perspective on CVD in Coimbatore Region extended by 52\%, from 1.50 million (2010) to 1.92 million (2018). Notwithstanding the wide heterogeneity in the regularity of cardiovascular danger factors across different areas, CVD has created as the fundamental wellspring of death in all bits of Coimbatore Region, including progressively deplorable states and rural districts [8]. The Evaluation of the regular is described with the aid of the switch of financial factors; smoker utilizes and get outcome is very low of the dust usage have gotten regularly depending with these from minimum financial related institutions [6]. Moreover, individuals from lower money related establishments once in a while don't get perfect treatment, inciting less blessed outcomes [2]. Countering the pandemic requires the headway of methodology, for instance, the arrangement and incredible execution of confirmation based course of action, stronghold of prosperity structures, and highlight on balance, early acknowledgment, and treatment with the use of both standard and inventive frameworks [1]. A couple advancing system based assessments are attempting these strategies [9].
\end{abstract}

Key Words: coronary disease, epidemiology, risk factor, Coimbatore Region survey and cardiovascular diseases.

\section{INTRODUCTION}

With the turn of the century, cardiovascular sicknesses (CVDs) have become the primary wellspring of mortality in Coimbatore Region.

Revised Manuscript Received on March 05, 2020.

* Correspondence Author

A. Zechariah Jebakumar*, Lecturer, Prince Sultan Military College of Health Sciences, Dhahran, Kingdome of Saudi Arabia.Email id: zechariah@psmchs.edu.sa.

Dr. R. Ravanan, Joint Director of Collegiate Education, Chennai Region. Survival Analysis of cardio patients. Email id: ravananstat@gmail.com.

(c) The Authors. Published by Blue Eyes Intelligence Engineering and Sciences Publication (BEIESP). This is an open access article under the CC BY-NC-ND license (http://creativecommons.org/licenses/by-nc-nd/4.0/)
In connection with the people of European family line, CVD impacts Indians in any occasion 10 years sooner and in their most beneficial midlife years [2].

For example, in Western masses only $23 \%$ of CVD passing occur before the age of 70 years; in Coimbatore zone, this number is $52 \%$. Furthermore, case loss infers able from CVD in low-compensation countries, including India, appears, apparently, to be significantly higher than in focus and significant compensation countries [9]. The World Health Organization (WHO) has surveyed that, with the present load of CVD, Coimbatore region would lose \$1.2 billion for the loss of productivity and spending on social protection over a 10-year time range (2008-2018) [3]. The purposes behind the high tendency to make CVD, the high case setback, and most raised less than ideal mortality consolidates natural instruments, social determinants, and their affiliations. Keeping an eye on this basic weight requires an understanding of both the natural and social determinants, and the flighty components major their participation, as well [9]. In this review, without help consolidate the CVD inconvenience in Coimbatore Region, the clarifications behind higher weight, expectation and treatment systems for CVD, and future methodology techniques to look for after [4].

The epidemiological advancement in the Coimbatore Region in the past 2 decades has been passionate; in a brief time allotment diagram, the staggering epidemiological properties have changed from overwhelming diseases, contamination of under sustenance, and maternal and youth sicknesses to noncommunicable afflictions (NCDs). The disease [11], inconvenience infer able from maternal issue, measles, protein-imperatives weak well being, and the runs 1 contamination decreased $>50 \%$ in the past 2 decades, while future during labor extended from 58.3 to 65.2 years, realizing the development of the people during a comparable period. In this way, the NCD inconvenience extended rapidly in Coimbatore region, with a relative climb in a tough situation attributable to CVD [4]. Practically $66 \%$ of the heaviest of NCD mortality in Coimbatore are correct presently contributed by CVD-related conditions. Notwithstanding wide heterogeneity in the ordinariness of danger factors across different regions (explained underneath), CVD is the fundamental wellspring of death in all bits of Coimbatore region, including the more awful states and common zones [5]. The contamination progress in Coimbatore in the past 2 decades seems as though the animated epidemiological change model with a quick move to the time of delayed relentless infections [3].

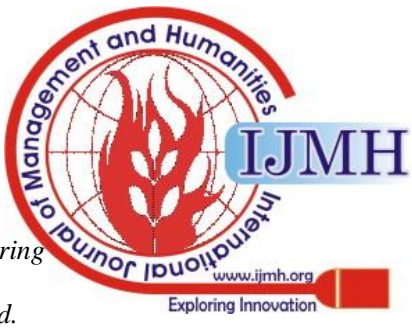




\section{LITERATURE REVIEW}

Joseph E. Ebinger, Andy Kim and Hongwei Ji [2020], the supposition that vascular physiology may essentially vary among ladies and men, a sex-explicit investigation of existing information could offer new bits of knowledge and expand our comprehension of sex contrasts in cardiovascular ailments., To assess whether longitudinal examples of circulatory strain (BP) rise vary among ladies and men during the existing course while considering gauge BP levels as the reference [3].

Without help directed sex-explicit examinations of longitudinal BP measures (144 599 perceptions) gathered for a time of 43 years (1971 to 2014) in 4 network based US associate investigations. The consolidated complete included 32833 members ( $54 \%$ female) spreading over ages 5 to 98 years. Information was examined between May 4, 2019, and August 5, 2019., Sex-explicit change in every essential BP measure contrasted and standard BP levels, got from staggered longitudinal models fitted over the age length, and new-beginning cardiovascular illness occasions., JAMA Cardiol. Distributed online January 15, 2020. doi:10.1001/jamacardio.2019.5306 [11].

Donald S Shepard [2020], The United States, like most countries around the world, is striving to improve its population's cardiovascular health. Recent results, however, are mixed [1]. On the favorable side, clinical medicine continues to improve [7]. For example, a December 2019 review chronicled 39 improvements in the diagnosis and management of cardiovascular disease just in the preceding six months [3]. 1 With the worrying sign, however, several risk factors due to lifestyle continue to worsen. The National Health and Examination Survey (NHANES) documented significant increases in the prevalence of obesity from 19992000 to 2015-16 (the most recent data) in both adults and youth. 2 More recent self-reported data through 2018 showed the prevalence of bothobesity3 and sedentary lifestyles has continued to worsen. Several randomized trials have shown how financial incentives can improve cardiovascular indicators. For example, a 16-week trial evaluated both a deposit contract (where participants deposited money, matched by the program that could return up to $\$ 252$ per month) and a lottery program (daily chances of $\$ 10$ or $\$ 100$ ) based on daily weight compared to daily monitoring without incentives [6]. Participants in the both incentive conditions had significantly greater odds of meeting the program goal of losing one pound per week than control participants [3]. The odds ratios were 7.7; (95\% CI, 1.4-42.7) for the deposit approach and 9.4 (95\% CI, 1.752.7) for the lottery [2]. 6 A subsequent one-year randomized trial with weekly incentives or penalties of \$20 found a highly significant 6.5 pound reduction. Received: December 20, 2019 | Published: January 16, 2020. Volume 13 Issue 1 - 2020002E [6]

Darrel P. Francis, Judith A.Finegold and PervizAsaria [2019] The World Health Organization (WHO) gathers mortality information coded utilizing the International Statistical Classification of Diseases (ICD) code [12]. Privately broke down IHD passings worldwide, somewhere in the range of 1995 and 2009 and utilized the UN populace database to ascertain age-explicit and straightforwardly and in a roundabout way ageinstitutionalized IHD death rates by nation and locale. IHD is the single biggest reason for death around the world, causing 7,249,000 passings in 2008, $12.7 \%$ of complete worldwide mortality [8]. There is more than 20-crease variety of IHD death rates between nations. Most elevated IHD death rates are in Eastern Europe and Central Asian nations; least rates in high salary nations [7]. For the working-age populace, IHD death rates are particularly higher in low-and-center pay nations than in high pay nations [6]. In the course of the most recent 25 years, ageinstitutionalized IHD mortality has fallen by the greater part in high salary nations, yet the pattern is level or expanding in some low-and-center pay nations [5]. Low-and-center pay nations currently represent over $80 \%$ of worldwide IHD passings [1].

\section{RESULTS AND DISCUSSIONS OF BURDEN OF CARDIOVASCULAR DISEASES IN COIMBATORE REGION}

As per the Global Burden of Disease study ageinstitutionalized assessments (2010), almost a quarter (24.8\%) of all passing in Coimbatore locale are owing to CVD (Figure I-I) [7]. The largest and faradized CVD demise pace of 272 for every 100000 populace in Coimbatore area is higher than the worldwide normal of 235 for each 100000 populace (Table 1) [2]. Be that as it may, there is a significant hole in information, particularly with respect to the reasons for death in provincial of the Coimbatore Region; Global Burden of Disease gauges depends on littler network based investigations [5]. Albeit verbal post-mortem examination information from India were gathered over 2004, they have not been dissected or discharged to the community, and they were excluded from the weight estimation [6]. At present, there are no broadly delegate observation information on the predominance of CVD and the mainstream patterns of CVD mortality in Coimbatore Region. Be that as it may [7], ongoing reports of 4 enormous forthcoming investigations from the Coimbatore district recommend a higher extent of mortality infer-able from CVD (40\%-52\%) and an ageinstitutionalized CVD death rate (122-216 for each 100000 populace in men and 136-388 for each 100000 populace in ladies) in examination with the Global Burden of Disease study (2018; Figure 1 - I \& II) [12]. Ischemic coronary illness (IHD) and stroke comprise most of CVD mortality in Coimbatore (85\%), with IHD is dominating (Figure 2) [3]. The proportion of IHD to stroke mortality in Coimbatore district is essentially higher than the worldwide normal, and is tantamount to that of Western industrialized nations (Figure 2) [6]. Together, IHD and stroke is liable for more than one-fifth (31.2\%) everything being equal and one-tenth of the long stretches of life lost in Coimbatore area (long periods of life lost is a measure that evaluates untimely mortality by weighting more youthful passing more than more seasoned passing). The long stretches of life lost owing to CVD in Coimbatore locale expanded by 60\% from 2010 to 2012 (31.3 billion to 41 billion) [2].

Albeit methodical investigations on IHD pervasiveness utilizing countrywide agent tests are not accessible, a few little cross-sectional examinations acted in various pieces of the nation propose fast increments in the IHD trouble in the course of recent decades (Figure 3A and 3B). 
In spite of the fact that the pervasiveness rates in grownups from various cross-sectional overviews led at various time focuses can't be legitimately looked at, the general patterns are educational [2]. The pervasiveness of IHD in 1970 in urban zones was $3 \%$, and expanded 8 -overlap to $\approx 15 \%$ by 2018.Similarly, it's more than quadrupled in provincial regions, from $2.1 \%$ to $8.5 \%$ somewhere in the range of 2013 and 2018. These pervasiveness gauges are likely a disparage of the weight, in light of the fact that the strategies for estimation depend on inhumane devices. Moreover, the higher case casualty among Indians following intense coronary disorder (ACS) could likewise bring about the underestimation of commonness [2]. The Macroeconomic Commission for Health assessed that irrefutably the quantity of IHD patients in Coimbatore locale will increment from 41 billion of every 2015 to 68 billion out of 2018 (a $\approx 74 \%$ expansion) [5]

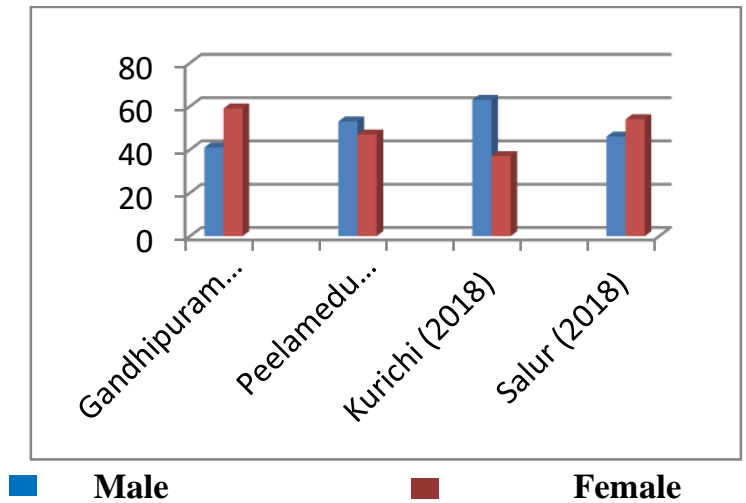

Figure i: CVD mortality as a proportion of total mortality (\%)

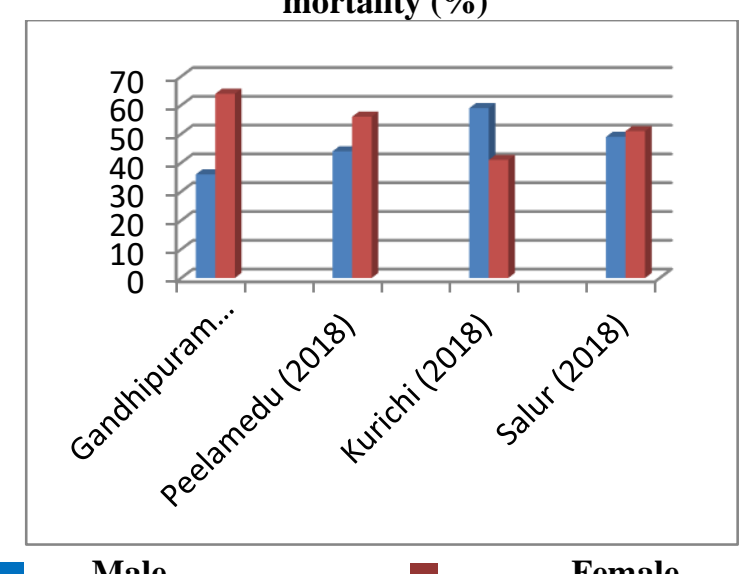

\section{Figure $i$ and ii.}

i, Duration of aerobic infection India loss of life relies upon arranging facts on account that possible immediate analysis also World Difficulty of disease pattern. Imminent investigations remembered for the picture stands (Urban area Gandhipuram), (Rural and Urban area Salur), (Rural area Peelamedu) and (Kurichi, Rural) [3].

ii, Age-institutionalized pace of aerobic infection, Coimbatore mortality established proceeding the World Difficulty Sickness appraisals additionally a few information can available drawing close knowledgeable. CVDs demonstrates cardio malady also World Difficulty Sickness [4].

\section{Figure ii: Age-standardized CVD mortality rate per 100,000 population.}

Table I. Age Standardized Death and Disability Rates of VD in Comibatore region.

\begin{tabular}{|l|c|c|c|}
\hline \multirow{2}{*}{\multicolumn{1}{|c|}{ Diseases }} & \multicolumn{3}{c|}{ Death per 100 000 Population } \\
\cline { 2 - 4 } & Male & Female & Total \\
\hline Endocarditis & $\mathbf{5 6 ( 2 9 )}$ & $\mathbf{5 3 ( 2 6 )}$ & $109(5 \mathbf{5 5})$ \\
\hline \hline Peripheral vascular disease & $43(31)$ & $39(23)$ & $82(3)$ \\
\hline \hline Aortic aneurysms & $8(3)$ & $6(2)$ & $14(5)$ \\
\hline \hline Atrial fibrillation & $18(7)$ & $10(4)$ & $28(11)$ \\
\hline \hline myocarditis and Cardiomyopathy & $\mathbf{5 ( 3 )}$ & $7(2)$ & $12(5)$ \\
\hline \hline Rheumatic heart disease & $1(0)$ & $1(1)$ & $1(1)$ \\
\hline \hline Ischemic heart disease & $7(3)$ & $6(2)$ & $13(5)$ \\
\hline \hline Others & $6(2)$ & $3(1)$ & $9(2)$ \\
\hline \hline Total Cardiovascular diseases & $144(78)$ & $125(82)$ & $268(87)$ \\
\hline \hline
\end{tabular}

In Comibatore region, the regular age yearly Heart Disease frequency \% was 132 for every 1 Lakh every 12 months (institutionalized toward the Coimbatore district populace) [4]. Despite the fact that the stroke rate and Heart disease connected instance casualty \% @ Coimbatore remain advanced compared with developing countries by and large, the rates are particularly higher among ladies [9].

Accessible micromanaging information propose of hemorrhagic Heart disease are much typical @ Coimbatore that popular populace [5]. Proportion of is coming heart disease to hemorrhagic heart disease death in Coimbatore stands under The Tamil Nadu normal away from near, through hemorrhagic Heart Disease death journey prevalent (Figure ii) here mirrors are generally low propelled phase coming from ideological progress popular Coimbatore at correlation through populaces [1].

Hypersensitive coronary illness, between different cardio stands critical issue happening Coimbatore district, through 11549 passings popular 2016; here stands expansion based on $125 \%$ happening examination through quantity out from passings happening 2000. Disabled coronary illness additionally keeps on being an issue in a few sources from India, through any expected 99565 passings (6 for each 1 Lakh populace) happened in 2010 [7]. Dependable state wide information happening sick coronary illness, trouble stands no more accessible from Coimbatore as a result of the distinctions in the definitions utilized in existing investigations [12]. Nonetheless, the accessible assessments propose that the rheumatic coronary illness commonness remains popular scope based on 2.6 - 3 for every one thousand people (3 to 3.4 billion) [2].

In contrast to Western populaces, atrial fibrillation has all the earmarks of being less normal in Coimbatore, with rheumatic coronary illness adding to about 33\% (11.6\%) like material trouble [3]. This information depends scheduled Random Assessment like deep duration Indicant analysis vault, a library like 12500 Sick peoples starting 54 nations, also 2700 Sick people against Coimbatore, introducing to crisis divisions [10]. As far as personally could possibly know there are no across the country appraises on the pervasiveness and frequency of atrial fibrillation, cardiovascular breakdown, and cardiomyopathy in Coimbatore [12]. 


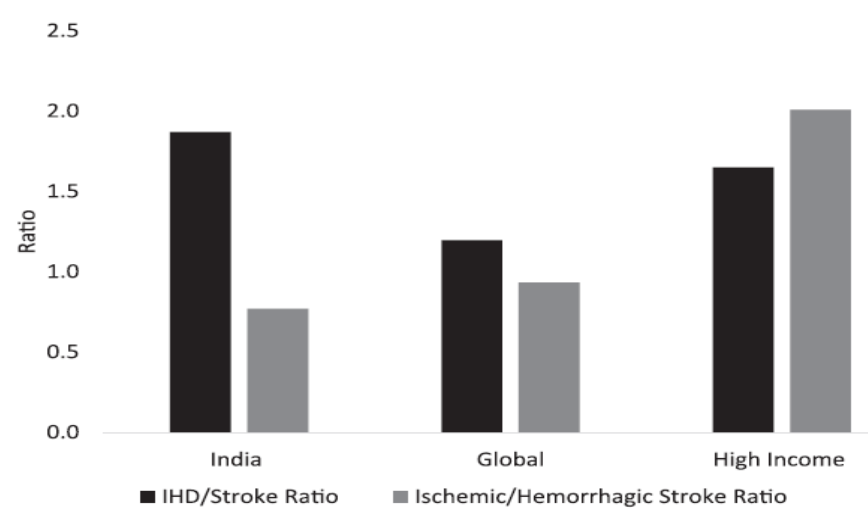

Figure iii: Ratio Result of All over India

In view of World Difficulty like Sickness educate gauges, Commitment like material vibration also ripple toward general CVDs trouble in Coimbatore gives off an impression of being less [2]. Besides, the corresponding mortality and bleakness trouble owing to different sorts of CVD, for example, arctic aneurysms, fringe visual illness, also indicators remain additionally generally little [3].

\section{RISK FACTORS of CVDs}

Domestic Range information aimed at maximum hazard issues (except for tobacco) are not accessible [2]. Be that as it may, a few enormous fractious factional studies have been directed trendy Coimbatore trendy previous 371 months also without help give an outline like this investigation are following area. Significant late ideological examinations explains in Table ii [1].

The situation can assess such, presently, 364 billion people matured $\geq 180$ months expend smoking peoples at Coimbatore [9]. Dying trouble inferable from smoking peoples in Coimbatore remains enormous, in light of the fact that it is assessed to cause almost 1 million passing's every year. By and large, more than 33\% of grownups in Coimbatore (46\%) usage, smoking, through commonness \% shifting since $8 \%$ in Coimbatore $76 \%$ at north Coimbatore province like Diorama [1]. Smokeless people also tobacco like maximum widely recognized sorts like smoking utilized at Coimbatore [7]. In spite of the fact that the general pervasiveness of tobacco stands small (23\%), tobacco predominance stands difficult between male (31\%) then between ladies (4\%), also tobacco between people through not exactly essential instruction is higher for both genders (37\% and 4\% for people, individually) [9]. Her stands disturbing such smoking are useful for expanding quickly between youthful people (31 to 39 category) popular Coimbatore Region, through more extreme pace like increment between persons through lesser knowledge. Suggestion likewise proposes such research through smoking begins moderately ahead of schedule among kids in Coimbatore Region [11].
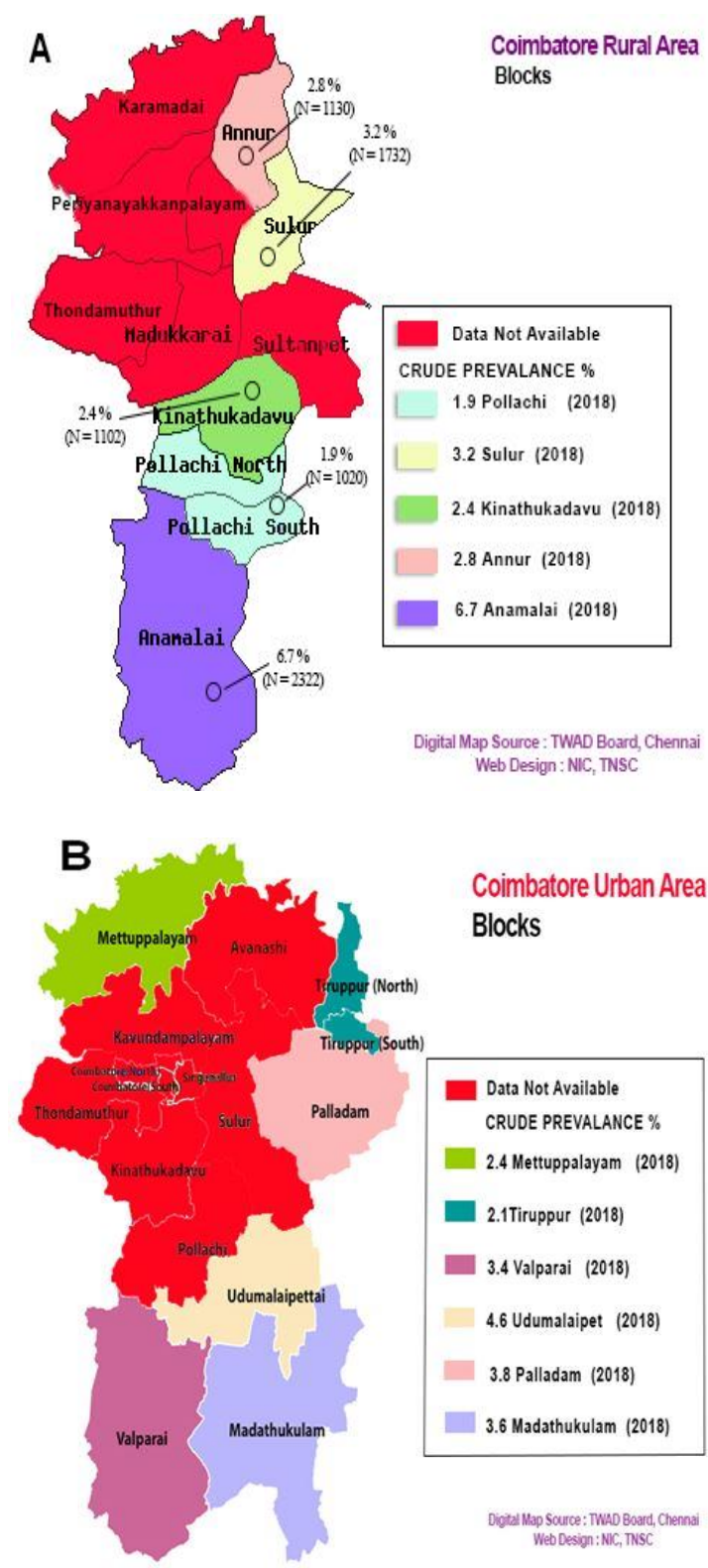

Figure iii (I \& II)

i, Common coronary contamination commonness \% now country Territories in Coimbatore [4]. The statistics now guide stand predominance; example, amounts stand popular brackets. Longer periods like basis information remain recorded now symbol important enclosures. Information after another examination trendy rustic Pollachi (2018) remain incorporated [9]. ii, Ischemic indicator infection frequency charge in town regions in Coimbatore place [4]. The numbers in the guide are the pervasiveness, with test estimates in brackets. The long stretches like basis information remain recorded now symbol important brackets [9].

Pace of utilization of products of the soil is low in Coimbatore; this is in opposition to the observation that Indians, being prevalently vegans, would expend sufficient amounts of foods grown from the ground. An enormous [1], broadly agent annoyed factional overview casing 245425 people now Coimbatore thru person announced information 
at utilization like foods grown from the ground, revealed such partial like populace away from study expended zeroes either just dollop like natural product popular seven days. Additionally announced familiar inclination trendy week by week utilization of organic product [2], with people in the most minimal financial strata devouring an extremely low amount of natural product. This is Likely clarified by using the sizeable cost of crisp merchandise of the soil [10]. Also, the spuds such stand devoured remains frequently burned at Coimbatore suppers, prompting imperative damage like small mineral. Indeed, straight popular double maximum monetarily rich place, Coimbatore and India, World health organization suggested utilization like 6 products of the soil day by day is just seen among $24 \%$ and $1 \%$ of individuals, separately [12].

Time-arrangement information on supplementary admission caught after NSSO reviews show this in spite of the never noteworthy alteration now all out calorify utilization since 2010 to 2018, Indian obese admission expanded after 33 - 45 \& after 46 to 61 trendy countries also town people, individually. Mostly hydrogenated vegetable oils with high transfer substance add to a critical extent of absolute fat admission in India [5], also Utilization based on incompletely originated tater lubricant stands normal, especially town grown-up ghetto inhabitants having a place with the least financial status (SES) [6]. Regardless of the way such level based on sugar admission keeps continue decently relentlessly, the use of urbane corny things extended current examination through the uses based on entire ounces [7].

Details in body movement at Coimbatore stand scanty [3]. The ICMR-INDIAB study surveyed the physical action utilizing the World body Movements Questions are 15336 people matured $\geq 240$ months [6]. Each two people from INDIAB educate remained measured body idle. Moreover, $<10 \%$ of the considered populace occupied with recreational physical movement. Physical idleness existed developed at town zones, as ladies, also as people out from larger than ESE [8]. The investigation on 5287 people against urban areas, didn't discover any distinction in body movement, altitude among bunches dependent against small depressed huge instruction standing [10]. Be that as it may, with a huge report led in modern settings, recreation time physical action indicated a converse social inclination [11].

Commonest belongs to tension zones at Coimbatore district act gauged through obtaining 25\% (25\% are town zones also $19 \%$ active provincial territories) [3]. The quantity away from people through tension stands relied upon towards twofold after 227 billion of every 2008 - 2018 billion through 2025 [4]. Coimbatore district, Normal circulating strain takes expanded Brand new the preceding 2 a long time, although in maximum Western countries, it has declined. The social slope for high blood pressure is misty [4]. Albeit more than one concentrating from the urban settings document an opposite social inclination, with the higher not unusual among humans from low SES, others record no distinctions [5]. Information from low-earnings nations (eighty three\% of the members being from Coimbatore district) from (PURE), likewise display that low instructive repute is related through minor paces of mindfulness, remedy, also can monitoring of high blood pressure [6]. The commonness, remedy, and manage paces of diabetes mellitus and hypertension stay abridged in Figure iv.

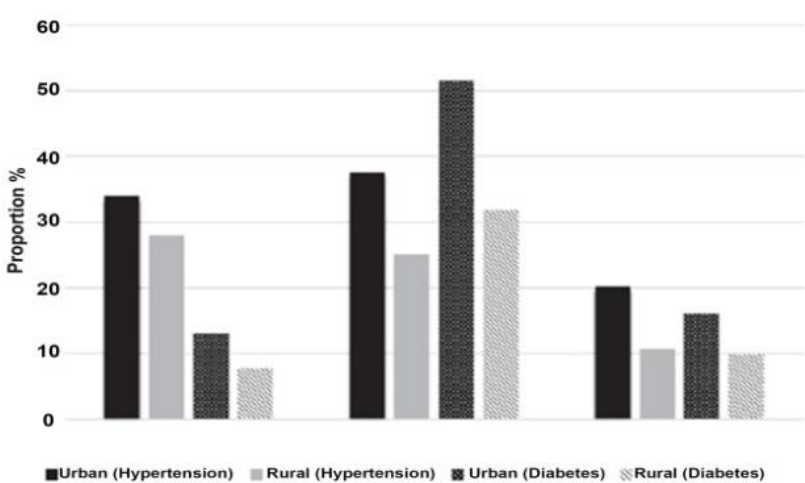

Figure iv: Treatment, Control and Prevaence result in urban and rural area in Coimbatore Region.

Figure iv. Commonly, Remedy, and manage high blood pressure and diabetes mellifluous at city also provincial Coimbatore. Tension statistics is gotten from the deliberate audit and meta-examinations. Diabetes mellifluous information is gotten from the ICMRINDIAB Study [4].

In the town territories of Coimbatore, the commonness of diabetes mellifluous takes nearly accelerated inside the previous twenty years, from nine percentage - seventen percentage [11], also can rustic zones it has about multiplied, since two percentage to nine percentage on 2010, the Global Diabetes Alliance assessed sixty five billion individuals in Coimbatore consumed diabetes mellifluous, a excessive extent of who have been grown-up of salaried stage can evaluated that the quantity of people with diabetes mellifluous will increment to a disturbing 101 billion by using 2030 [12]. A gauge depending on India look at demonstrates that the quantity of people in India through predicates is sixty four billion. Moreover, in mild of epidemiological statistics additionally transformation fees amongst manage bunches in mediation examines, the trade price from predicates of debts mellifluous is great. Diabetes mindfulness and manage are negative in provincial locales in correlation with urban regions (Figure four). Diabetes mellifluous continues on having a positive social angle, except for specific settings, as an instance, present day paintings web sites. Be that as it is able to, an as of overdue closed examination of chance components of CVD in urban and rustic Coimbatore proposes that there may be no difference in the predominance of diabetes mellifluous across specific SES gatherings.

Sequential epidemiological investigations in India suggest a fast ascent within the suggest stages of all out cholesterol, low-thickness protein, cholesterol, non-highthickness protein cholesterol, and triglycerides [2]. The massive extent of individuals had in any event lipid variant from the norm; simply $20 \%$ had all lipid parameters within the typical variety. The most on the whole watched lipid variant from the norm become low excessive-thickness protein, ldl cholesterol [7]; this became watched all the extra regularly among those with decrease stages of training. In an research directed in Coimbatore, low schooling and SES have been related with low excessive-thickness protein ldl cholesterol and excessive triglycerides [1]. 
Be that as it can, hyper ldl cholesterol, characterised as all out ldl lipid five mmol per Litter, is commonly low regular between humans by smaller than SES better than gatherings [5]. Not at all communal slope changed into visible inside the ICMR-INDIAB look at for high, lowthickness protein cholesterol [3]. Like diabetes mellifluous and hypertension, manage of epidemic turned into reduction in country populaces than in city populaces.

Aside from the hazard factors referenced in the past areas, long haul material hardship, undesirable residing conditions, and elevated degrees of pressure additionally seem to add to overabundance Cardio chance among socially burdened gatherings in India [8]. Early-life impacts, especially in the initial 1000 nights (the time of origination through the initial 2 years), had been punitively ensnared to assume a huge job in the beginning of Cardio also its hazard factors during grown-up life [6]. Maternal ailing health, placental inadequacy, and the subsequent factors during has been conjectured to be related with low-muscle-excessivefats frame structure (slim fat kid), decrease of $\beta$-cellular mass, also less glimmering in the kidney [3]. In the Coimbatore Regio Cohort have a look at, bounce back adipose and weight advantage in the course of adolescence among the a age, while of 2 and 12 had been demonstrated to be identified with a better penchant to create hypoglycemia as youthful grownups. Information produced from the progressing inter generational associate investigation, including kids and guardians in the South Indian territory of Telemann will probably give dependable logical proof on long haul impacts of day by day life under nutrition in danger of Cardio infertility [3]. Notwithstanding these natural systems, social factors additionally seem to assume a job. Early-life impacts bring about weakening insight, low school execution, and low efficiency, which are all related with overabundance cardiovascular hazard factors [7].

\section{CVDS TREATMENT \& PREVENTION}

Development like the Cardio scourge like Coimbatore represents an extraordinary test to its well being frameworks [9]. Be that as it may, usage of information on CVD decrease procedures from Western nations gives a chance to battle the scourge like Coimbatore [8]. Can decrease recent cardio death in this state stage adjustments recent populace stage adjustment recent like manner chance variables and restorative treatments, with the greater part away from decrease recent death credited to enhancements in population stage hazards cause like collateral, smoking, and pulse [3].

As far as a person could possibly know, there is no information assessing macroeconomic approach changes and non personal meditation on CVD in India. Be that as it may, displaying examines proposed that generous advantages could be picked up by forcing charges on sugar, tobacco, and palm oil -improved drinks like Coimbatore [4]. Interest preserve evaluated this type of $23 \%$ cost of glucose -progressed drinks call for reduce heavy also stoutness pervasiveness by $3 \%$ also rate like pattern two debaters mellifluous thru 3\% [5]. Also, a 22\% assessment above crown lard buys do relied upon to deflect $\approx 373000$ passing (a $1.5 \%$ total decrease in Cardio passing) against my cardio areas of localized necrosis (MIs) also heart disease past a time away from ten years [6]. About 420000 CVD occasions (stoke and MIs) also 82111 passing (a 6\% decrease) may be turned away by a balanced decrease current spice admission (lessening admission by way of three g/d, over a thirty year time frame) between moderately elderly Coimbatore [7]. At long last, sans smoke enactment and tobacco tax collection together may turn away $27 \%$ of Heart disease in the Coimbatore such manner [2], Arrangement choices Indian Government to elevate the extract obligation as somker items in 2016 up to $76 \%$ and to impose another $6 \%$ charge on sugar-improved drinks are empowering [12]. Extract obligation as smoker items has been expanded from $13 \%$ to $75 \%$ for cigarettes, $13 \%$ to $18 \%$ in dish Marsala (seasoned smoker), 53\% to $57 \%$ in manufacturing smoker, also $63 \%$ to $74 \%$ on biting smoker. In any case, our bodies, which are normally utilized by Indians, weren't enough burdened on the grounds that they're assembling is characterized at the time that little client state [4]. Ensuing the milestone Asia elevated stage gathering at NCDs also the support of a worldwide activity method hundred and ten since the anticipation furthermore, authority based on NCDs in WHO, Indians wear built up nationally observing structure to accomplish group objectives agreed away using World Health Organization [5]. The major point remembers a 33\% cousin decrease for each tobacco and salt utilization on 2025 [6].

\section{IMPROVING EFFICIENCY OF CARE}

In spite of the fact that savvy mediation is accessible from the anticipation and manipulate of the Cardio hazard element, therefore significant boundaries of theory far reaching usage popular India, which includes small location [10], quotes, lacking mindfulness, bad utilization of proof established intercessions, and occasional adherence quotes [11]. Creative techniques should be created and tried in Indian settings to defeat these difficulties [2]. A few methodologies that might improve the proficiency of care incorporate joining data, correspondence innovation instruments, and errand moving and task sharing procedures, also (examined beneath) [6]. A few such activities are presently being tried in India; one model is the assessment of a mind boggling intercession technique utilizing imaginative portable well being (m Health) programming applications [5]. This m Health stage pops top gather Out Patient's well being profiled, give choice help to clinical consideration, and go about as a checking and input instrument to be used in essential consideration framework. Group irregular preliminary assessing the utilization likewise opinion choice help apparatus for the executives like tension out-of-time finished in Coimbatore Region, in 16 essential social insurance focuses [4]. This examination inferred that electronic clinical choice emotionally supportive networks are both compelling and savvy in the administration of hypertension in asset obliged essential consideration settings [3]. What's more, a multifaceted methodology utilizing versatile innovation to help rustic essential human services specialists and bleeding edge wellbeing laborers in CVD chance administration has been created and was executed in 18 essential well-being focuses and 54 towns in country Coimbatore Region including $\approx 15$ 000 grownups matured forty years in big Cardio occasion hazard 127 [2].

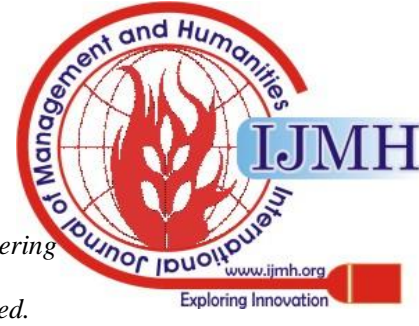


Aftereffects like those examinations can possibly illuminate arrangement on marketable methodologies to develop the productivity of the well-being framework in overseeing CVDs [1].

\section{WELLBEING STRUCTURE AWARENESS \& EXCELLENCE OF CAUTION}

The revs an immense deficiency in the accessibility of prepared HR for individual services and well-being research center. Lack of a prepared personalize seen at all degrees of medical services, along with masters [2], essential consideration doctors, and cutting edge well-being laborers. There is a lopsided appropriation in numbers and in the nature of the social insurance workforce, among rustic and urban India, yet additionally between and inside various locales and states. Improving the human asset limit with regards to the anticipation also monitor like Cardio ought to bean, Indian need, and endeavors ought to in both guarantee evenhanded conveyance of accessible assets in each provincial also town are [3].

Because rising expense and annihilating financial results for Cardio care [10], Advancement of the guidelines of a kind also the appropriation of practical case the board of Cardio, particularly in optional also tertian framework, ought to be viewed as needing [11]. Element development activities should be energized, and need ought to receive to nonstop best observing and improving [9]. Customary execution reviews should do completed distinguish geniuses identified with nature affaire [12]. Continuous input against those exhibition reviews and auspicious remedial activity may improve the conveyance of generally speaking nature of care [1].

Table ii: Gaps in Knowledge and Future Directions

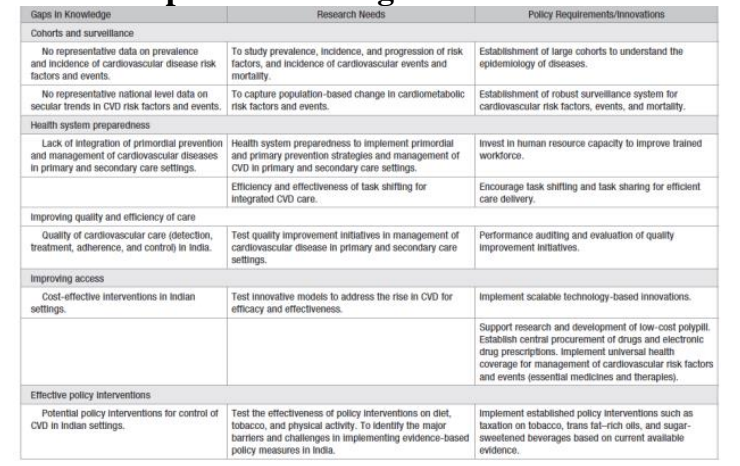

The limit with respect to CVD inquire about additionally should be reinforced to produce proper contextualized proof. A few projects are in progress in India with assistance more national also overall financing, Department of Biotechnology and science, trust and technology this endeavor will help accomplish the objective of expanding the quantity of prepared specialists in India [3].

\section{ACCESSBLE IMPROVE}

Regardless of the affirmation of Cardio as a significant general medical issue, have right of entry into cardiovascular consideration entrains moderately serious. These are contemplated within the terrible discovery, remedy, also loyalty through confirm primarily based medicine choices surrounded by Coimabtore. Essential wellbeing framework in India has generally been designed for the administration of transmittable maladies, maternal and kid human services, and vaccination [1]. The combination of CVD preventive consideration in the essential social insurance framework in India, thus requires extraordinary consideration, with a requirement for imaginative models in well-being advancement.

A few such activities robing tried. One model is a team take a look at style "Adequacy of diet and way of life mediation through data instruction [5], specialized devices with Angara Wadi laborers (bleeding edge well-being laborers) as the focal point of information scattering for hypertension hazard decrease (DISHA)," which is subsidized by the Medical Research under India [8]. The DISHA venture is a bunch irregular, managed preliminary trying out the viability of well-being advancement exercises conveyed via prepared bleeding edge well-being laborers on populace level changes in circulating strain [7]. This investigation is the biggest bunch irregular, managed preliminary in Coimbatore, along 211 groups and almost 36000 examination members, also another ability to identify epidemiological noteworthy changes in circulating strain. The aftereffects of another enormous bunch irregular preliminary, assessing the mediation technique of errand moving to network well-being laborers for the administration and line out patients need excessive Cardio hazard, alongside help from a choice emotionally supportive network, are likewise expected; this examination occurred in Coimbatore, Tamil Nadu and Delhi, China. Essentially, a translation preliminary (financed by the Lungs [6], Blood and Heart such assessed an intercession methodology of undertaking moving to think about the administration of diabetes mellifluous (helped by electronic well-being records and a choice emotionally supportive network of tertiary and optional consideration focuses) has finished the examination observe-uprear middle time of 30 months [2]. previous, one more multi-center family \% group irregular preliminary has finished enrollment; this investigation includes network well-being laborers in essential avoidance techniques at the network level to elevate adherence of medicines to forestall CVDs [9].

\section{OPERATIVE STRATEGY INVOLVEMENTS}

Coimbatore turned into one of the principal nations to sanction the structure show on MPOWER and smoker controller systems (measures presented by means of the WHO which might be proposed to aid the nation level usage of viable mediation to lessen the interest for tobacco) by authorizing The smoker and Cigarette materials Act; this remembers the dis allowance of smoking for open places, the restriction of commercial, advancement [3], and also support of smokers items, the forbid-dance of offer of smoker to minors, necessity of well-being admonitions on smoker items, and the guideline of substance of smoker items. Be that as it may, in the Indian setting, usage of those processes stands test [4]. For instance, just about portion particular area (49\%) must instruments for checking arrangements under the demonstration [5].

Actualizing a salt decrease methodology at Coimbatore aimed at monitoring circulatory strain is likewise a test, for a few reasons [6]. 
To start with, salt is utilized for example a automobile aimed at salt segmentation towards decreasing the commonness of salt insufficiency issue in India [7]. Except if methods remain occupied towards expanding salt satisfied material, in an interview through specialists Inside the discipline of endocrinology, Without help can also deliver conflicting well-being correspondences furthermore, force to surprise with objective populace [8]. Additionally, salty stands frequently included making also some approach mediation towards lessen salty usage authorized in this way need dynamic network support also conduct alteration [9].

Approaches also projects include effect cardio well-being spread a wide scope of territories past the medicinal services area, including improvement, financial matters, farming [10], urban foundation, the earth, etc. Along these lines, investigate in cardiovascular some of social determinants are used well-being should be elevated to decidedly impact approach choices, made by non-health offices inside the administration format of the state and central Gov in Coimbatore, a certain take significant well-being suggestions [11].

\section{CONCLUSION}

Cardio stand significant overall health problem at Coimbatore, regularly influencing max beneficial long periods an individual's life. The ideological advancement shows away differently in different districts of Coimbatore on account of fluctuated monetary improvement. Divergent connections among CVD and SES chance elements remain apparent in zones are in different periods of ideological advance. In any case, when use smoking also tension in town area are is being dependably associated with lower stages to train given salary. As the country progresses forward the course of ideological modification, another danger component of CVDs might advance on show similar common leanings. Assuming responsibility for the CVDs epidemic in Coimbatore area require all of the accomplices, along with the strategy producers, to perceive and location the social reason a certain act unequivocally connected to CVD hazard factors and to the related grimness also, fatality. The growing CVD inconvenience and the hurting out come her takes scheduled populaces, families, and people require earnest thought. Inventive techniques remain probable to break the measure the CVDs plague in benefit reduced locations in Coimbatore. To location the budgetary prong in the heaviness of disease and human administrations demand of Indians, extra resources ought to be composed toward applying the ebb and flow information corrupt toward stem the CVDs scourge in arrangement, research fields, limit building and programs.

\section{REFERENCES}

1. Saperia GM, Yeon SB, Downey B, et al. What's new in cardiovascular medicine? Up To Date. 2020.

2. Lin Yang, Chao Cao, Elizabeth D Kantor, et al. Trends in Sedentary Behavior Among the US Population. JAMA. 2019;321(16):15871597

3. Stephan S, Tuchman A, Yao S. The Impact of Soda Taxes: PassThrough, Tax Avoidance, and Nutritional Effects. USA: Stanford University Graduate School of Business; 2019. p. 19-21.

4. Du M, Tugendhaft A, Erzse A, et al. Sugar-Sweetened Beverage Taxes: Industry Response and Tactics. Yale J Biol Med. 2018;91(2):185-190.

5. Centers for Disease Control and Prevention. National Health and and Prevention; 2017. p. 1-2. Nutrition Examination Survey. USA: Centers for Disease Control

6. Lancellotti P, Pibarot P, Chambers J, et al. Recommendations for the imaging assessment of prosthetic heart valves: a report from the European Association of Cardiovascular Imaging endorsed by the Chinese Society of Echocardiography, the Inter-American Society of Echocardiography, and the Brazilian Department of Cardiovascular Imaging. European heart journal cardiovascular Imaging. 2016;17(6):589-590.

7. Jeemon P, Narayanan G, Kondal D, Kahol K, Bharadwaj A, Purty A, Negi P, Ladhani S, Sanghvi J, Singh K, Kapoor D, Sobti N, Lall D, Manimunda S, Dwivedi S, Toteja G, Prabhakaran D; DISHA study investigators. Task shifting of frontline community health workers for cardiovascular risk reduction: design and rationale of a cluster randomised controlled trial (DISHA study) in India. BMC Public Health. 2016;16:264.

8. Lauby-Secretan B, Scoccianti C, Loomis D, et al. Body Fatness and Cancer Viewpoint of the IARC Working Group. $N$ Engl J Med. 2016;375(8):794-798.

9. Anchala R, Kaptoge S, Pant H, Di Angelantonio E, Franco OH, Prabhakaran D. Evaluation of effectiveness and cost-effectiveness of a clinical decision support system in managing hypertension in resource constrained primary health care settings: results from a cluster randomized trial. J Am Heart Assoc. 2015;4:e001213. doi: 10.1161/JAHA.114.001213.

10. Sakr SA, Abdel-Shakour H, Ramadan MM. Successful fibrinolytic treatment of prosthetic heart valve thrombosis using streptokinase. Acta clinica Belgica. 2015;70(3):159-166.

11. Gunduz S, Ozkan M, Yesin M, et al. Prolonged Infusions of LowDose Thrombolytics in Elderly Patients with Prosthetic Heart Valve Thrombosis. Clinical and applied thrombosis/hemostasis: official journal of the International Academy of Clinical and Applied Thrombosis/ Hemostasis. 2015.

12. Ozkan M, Gunduz S, Gursoy OM, et al. Ultraslow thrombolytic therapy: A novel strategy in the management of PROsthetic MEchanical valve Thrombosis and the prEdictors of outcomE: The Ultra-slow PROMETEE trial. American heart journal. 2015;170(2):409-418.

13. Clark H. NCDs: a challenge to sustainable human development. Lancet 2013; 381: 510-11.

14. Kumar RK, Tandon R. Rheumatic fever \& rheumatic heart disease: the last 50 years. Indian J Med Res 2013; 137: 643-58.

15. Padwal RS. Obesity, diabetes, and the metabolic syndrome: the global scourge. Can J Cardiol. 2014;30:467-472. doi: 10.1016/j.

16. cjca.2013.11.004.

17. Woodward M, Huxley R, Ueshima H, Fang X, Kim HC, Lam T-H. The Asia Pacific Cohort Studies Collaboration: a decade of

18. achievements. Glob Heart 2012; 7: 343-51.

19. Khalili D, Hadaegh F, Soori H, Steyerberg EW, Bozorgmanesh M, Azizi F. Clinical usefulness of the Framingham cardiovascular risk profile beyond its statistical performance: the Tehran Lipid and Glucose Study. Am J Epidemiol 2012; 176: 177-86.

20. Florez H, Castillo-Florez S. Beyond the obesity paradox in diabetes: fitness, fatness, and mortality. JAMA. 2012;308:619-620. doi: 10.1001/jama.2012.9776.

21. 19 Murray CJ, Ezzati M, Flaxman AD, et al. GBD 2010: design, definitions, and metrics. Lancet 2012; 380: 2063-66.

22. Thompson S, Kaptoge S, White I, et al. Statistical methods for the time-to-event analysis of individual participant data from multiple epidemiological studies. Int J Epidemiol 2010; 39: 1345-59.

\section{AUTHORS PROFILE}

A.Zechariah Jebakumar, Lecturer, Prince Sultan Military College of Health Sciences, Dhahran, Kingdome of Saudi Arabia. Survival Analysis of cardio patients. Email id: zechariah@psmchs.edu.sa.

Dr.R.Ravanan, Joint Director of Collegiate Education, Chennai Region. Survival Analysis of cardio patients. Email id: ravananstat@gmail.com. 